document any similar environmental exposures or events in either of the mothers' pregnancies. The possibility of a neural crest disorder with low penetrance in the father offers the most likely explanation for the occurrence of half sibs with these disorders.

\footnotetext{
References

1 Mellins RB, Balfour HH, Turino GM, Winters RW. Failure of automatic control of ventilation (Ondine's curse). Medicine (Baltimore) 1970;49:487-504.

2 Haddad GG, Mazza NM, Defendini R, et al. Congenital failure of automatic control of ventilation, gastrointestinal motility and heart rate. Medicine (Baltimore) 1978;57:517-26.

${ }^{3}$ Bower RJ, Adkins JC. Ondine's curse and neurocristopathy. Clin Pediatr 1980;19:665-8.

${ }^{4}$ Stern M, Hellwege HH, Gravinghoff L, Lambrecht W. Total aganglionosis of the colon (Hirschsprung disease) and congenital failure of automatic control of ventilation (Ondine's curse). Acta Paediar Scand 1981;70:121-4.

${ }^{5}$ Guilleminault C, McQuitty J, Ariagno RL, et al. Congenital central alveolar hypoventilation syndrome in six infants. Pediatrics 1982;70:684-94.
}

${ }^{6}$ Pettersen B, Tunnel S. Congenital central alveolar hypoventila $=$ tion syndrome (CCHS) and Hirschsprung's megacolon (HM) $\overrightarrow{0}$,
report of a seventh case. Am J Hum Genet 1986;39:75A.

${ }^{7}$ Ilbawi MN, Idriss FS, Hunt CE, et al. Diaphragmatic pacing in? infants: techniques and results. Ann Thorac Surg 1985;40: 323-9.

${ }^{8}$ Okamoto E, Ueda T. Embryogenesis of intramural ganglia of the gut and its relation to Hirschsprung disease. J Pediatr Surgo 1967;2:437-43.

9 Taguchi T, Tanaka K, Ikeda K. Fibromuscular dysplasia of arteries in Hirschsprung disease. Gastroenterology 1985;88: 1099-103.

10 Tam PKH, Lister J. Development profile of neuron specific enolase in human gut and its implications in Hirschsprungo disease. Gastroenterology 1986;90:1901-6.

1 Jacobs-Cohen RJ, Payette RF, Gershon MD, Rothman TP Inability of neural crest cells to colonize the presumptiven aganglionic bowel of Is/Is mutant mice: requirement for a permissive microenvironment. J Comp Neurol 1987;255;425-38.

Correspondence to Dr J N Bodurtha, Departmento of Human Genetics, Medical College of Virginia, Box 33, MCV Station, Richmond, Virginias 23298-0033, USA.

\title{
Holoprosencephaly: variation of expression in face and brain in three sibs
}

\author{
CASPER P ZWETSLOOT*, OEBELE F BROUWER†, AND \\ PETRA D MAASWINKEL-MOOY \\ *Department of Neurology, †Division of Child Neurology, and $\ddagger$ Department of Clinical Genetics, \\ University Hospital Leiden, The Netherlands.
}

SUMMARY A family is described containing three sibs with holoprosencephaly. They showed a striking diversity of both cerebral and facial abnormalities. Autosomal recessive inheritance seems most likely. Because of the great variety in expression of this disorder, it is of importance for genetic counselling to examine both sibs and parents.

Holoprosencephaly is a malformation disorder comprising a basic defect in the development of the embryonic forebrain, which is often associated with facial anomalies. ${ }^{1}$ The aetiology is heterogeneous. We report a family containing three sibs with holoprosencephaly showing a striking variation in expression of both cerebral and facial abnormalities. No similar published report could be found.

Received for publication 19 July 1988.

Accepted for publication 28 September 1988.

\section{Case reports}

CASE 1

The first child, a girl, was normocephalic (OFC $33 \mathrm{~cm}, 50$ th centile $=34 \mathrm{~cm}$ ) and had shortening of the frontal skull, flattening of the nose, and severe $>$ microphthalmia of the right eye with a normal left? eye. She was treated for seizures on the first day andN she died two days later.

Necropsy showed shortening of the anterior fossa and hypoplasia of the lamina cribrosa. The brainw (weight $255 \mathrm{~g}$ ) showed a monoventricle, a marginalo frontal indentation, hypoplasia of the frontal cortex and aplasia of the corpus callosum and the olfactory bulbs. No other congenital defects were found.

CASE 2

The second child, a boy, died on the first day of life. $\stackrel{\cap}{\Omega}$ He was microcephalic (OFC $27 \mathrm{~cm}$, 2nd centile $=\mathbb{\mathbb { Q }}$ $32 \mathrm{~cm}$ ) and had a proboscis of $3.5 \mathrm{~cm}$ protrudingo from the glabellar region between two extremely 
dysplastic and hypoplastic eyeballs. He had no nose and the mouth was very small.

Necropsy showed shortening of the anterior fossa and agenesis of the lamina cribrosa. The brain (weight $80 \mathrm{~g}$ ) had a monoventricular, bag shaped telencephalon with agenesis of the septum pellucidum, the corpus callosum, and the olfactory bulbs. No other congenital defects were found. Chromosomes were normal.

CASE 3

The proband, the youngest child, a four year old boy, was admitted because of epileptic fits. He was born at 37 weeks after an uncomplicated pregnancy. His birth weight was $3860 \mathrm{~g}$ with an OFC of $34 \mathrm{~cm}$ (50th centile). At the age of three months a left sided cleft lip and palate was closed. Because of brachycephaly, a CT scan was performed at five months and showed bifrontal cortical atrophy, absence of the corpus callosum, and an interhemispheric fissure that could be traced from the occipital to the frontal pole. At the age of eight months diabetes insipidus was diagnosed.

Examination on admission showed a severely retarded, microcephalic boy (OFC $47 \mathrm{~cm}$, 2nd centile $=48 \mathrm{~cm}$ ) with a scar on his upper lip, asymmetrical nostrils, a small penis, undescended testes, a divergent strabismus, and spastic tetraparesis (fig 1). He smiled at cuddling sounds and there was eye contact, but there were no intentional movements. Ophthalmological examination showed right optic atrophy and coloboma-like features of the left papilla. Another CT scan showed almost complete absence of both frontal lobes (fig 2). Extended laboratory investigations including chromosomal examination and endocrine screening showed no further abnormalities.
The parents were healthy and non-consanguineous. The mother was healthy during all pregnancies and did not take any medication. Physical examination of both parents showed no abnormalities, particularly no signs of hypotelorism, anosmia, or palatal or dental abnormalities. A six year old brother had developed normally. $\mathrm{He}$ showed no obvious dysmorphic features. Further examination was not permitted.

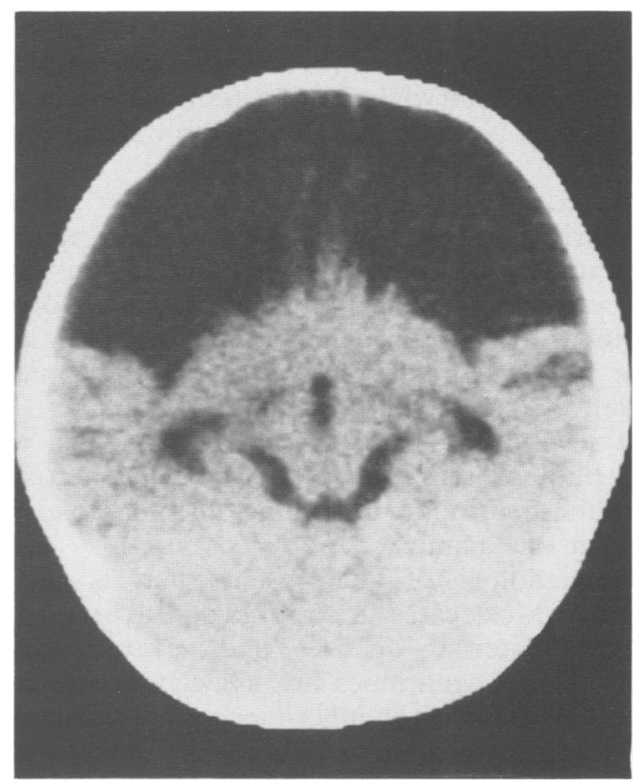

FIG 2 CT scan at four years of age showing loss of frontal brain parenchyma, resulting in a wide frontal pericerebral cerebrospinal fluid space.

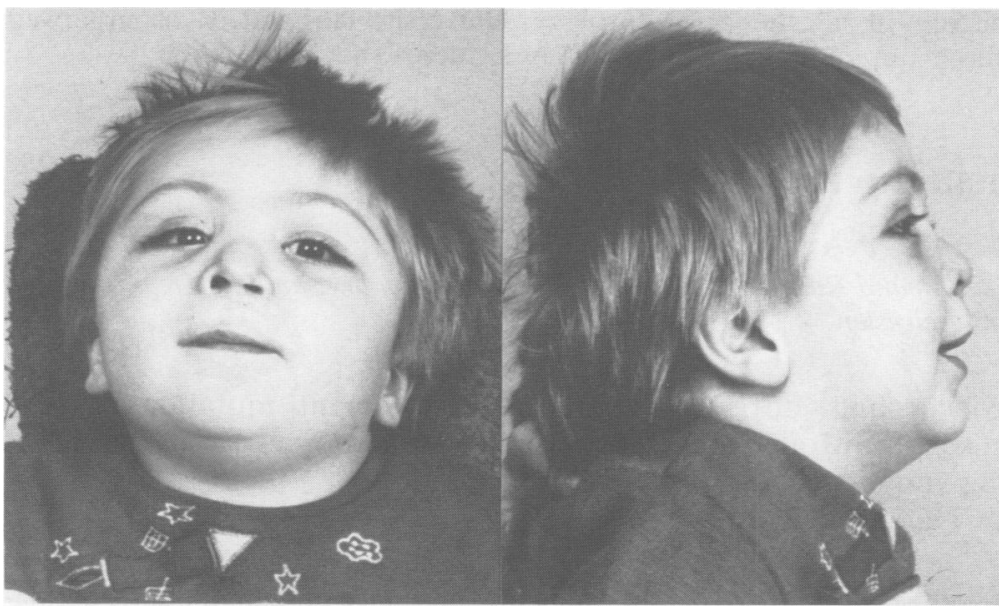

FIG 1 The proband. 


\section{Discussion}

Holoprosencephaly implies a whole or undivided forebrain. It includes a broad spectrum of abnormalities ranging from complete failure of differentiation of the telencephalic vesicles to a partial fusion of otherwise well developed hemispheres. According to DeMyer, ${ }^{1}$ three cerebral types can be recognised: alobar, semilobar, and lobar. As a result of diencephalic dysgenesis, endocrine disorders are sometimes present. ${ }^{2}$

There is often an association with a range of facial midline deformities, ${ }^{3}$ probably resulting from a failure of embryonic interaction between the notochordal plate, the neuroectoderm of the brainplate, and the oral plate. ${ }^{4}$

The correlation shown by DeMyer et $a l^{3}$ and summarised as 'the face predicts the brain' is illustrated by the reported cases. The least affected sib (case 3) had a cleft lip, flat nose, hypotelorism, and lobar holoprosencephaly on CT scan. The next (case 1) had hypotelorism with microphthalmia of the left eye and semilobar holoprosencephaly. The most severely affected (case 2) had cyclopia with alobar holoprosencephaly. We were unable to find any published report describing a comparable variation in one family.

The aetiology of holoprosencephaly is heterogeneous. Most cases are sporadic. Environmental factors, maternal disease, and several distinct chromosomal syndromes are associated with it. ${ }^{15}$ Autosomal dominant inheritance with incomplete penetrance and wide variability, sometimes with minimal involvement, as well as autosomal recessive inheritance have been described. ${ }^{5}$

Although in most disorders with autosomal recessive inheritance the extent of the malformation is usually similar, the absence of minor signs in the parents, the negative medical history in all the pregnancies, and the fact that three out of four children in one sibship were affected makes auto- $\stackrel{\mathbb{P}}{?}$ somal recessive inheritance in this family most $\underset{\vec{\rho}}{\vec{\rho}}$ likely.

In a study of 30 families in which a child with a severe form of holoprosencephaly was born, Roach $\overline{\frac{O}{\omega}}$. et al found that two out of 35 subsequent children $\vec{\nabla}$ of 18 of the mothers had holoprosencephaly. The $\varrho$ empirical recurrence risk was estimated as $6 \%$ ळ $( \pm 4)$. Because of the wide variation in expression $\vec{\circ}$ of this disorder, extensive examination of sibs and $\vec{A}$ parents for minor manifestations, such as anosmia, $\vec{\omega}$ single central incisor, hypo- and hypertelorism, and hypothalamic-pituitary dysfunction, is essential for genetic counselling. If Mendelian patterns of inheri-î tance are established for particular families, the recurrence risk increases accordingly. ${ }^{16}$

The authors thank A Th Nyenhuis for referring the응 patient, Dr G J Vielvoye for reviewing the CT scans, and Professor J J P van der Kamp for critically $>$ reading the manuscript.

References
1 DeMyer W. Holoprosencephaly (cyclopia-arhinencephaly).
In: Myrianthopoulos NC, ed. Handbook of clinical neurology.
Vol 6(50). Amsterdam: Elsevier Science, 1987:225-44.
2 Hintz RL, Menking M, Sotos JF. Familial holoprosencephaly
with endocrine dysgenesis. J Pediatr 1968;72:81-7.
3 DeMyer W, Zeman W, Palmer CG. Familiar alobar holo- $\frac{0}{\Phi}$
prosencephaly (arhinencephaly) with median cleft lip and
palate. Neurology (Minneap) 1963;13:913-8.
Cohen MM, Jirasek JE, Guzman RT, Gorlin RJ, Peterson MQ.
Holoprosencephaly and facial dysmorphia: nosology, aetiology
and pathogenesis. Birth Defects 1971;7:125-35.
Cohen MM. An update on the holoprosencephalic disorders.
Pediatr 1982;101:865-9.
6 Roach E, DeMyer W, Conneally PM, Palmer C, Merritt AD.
Holoprosencephaly: birth data, genetic and demographic analy-
sis of 30 families. Birth Defects 1975;11:294-313.

Correspondence to Dr C P Zwetsloot, Departmento̊ำ of Neurology, University Hospital, Rynsburgerweg 10, 2333 AA Leiden, The Netherlands.

\section{Thanatophoric dysplasia in identical twins}

\section{D YOUNG*, I PATEL $\dagger$, AND A C LAMONT}

From the Departments of Child Health* and Radiology $\ddagger$, Leicester Royal Infirmary, and the Department of Geneticst, University of Leicester, Leicester.

SUMMARY Female twins concordant for thanatophoric dysplasia are presented. Monozygosity was confirmed using minisatellite DNA genetic fingerprinting. The evidence

Received for publication 8 July 1988.

Revised version accepted for publication 21 September 1988. supporting new dominant mutations as the $\stackrel{\text { ? }}{+}^{+}$ likely cause of thanatophoric dysplasia is reviewed.

Conflicting conclusions have been reached regard $-\frac{\mathbb{2}}{2}$ ing the mode of inheritance of thanatophoric dyspla- 